\title{
Immigrant students and their teachers - exploring various constellations of acculturation orientations and their impact on school adjustment
}

\author{
Andrea Haenni Hoti ${ }^{a}$, Christine Wolfgramm ${ }^{b}$, Marianne Müller ${ }^{a}$,SybilleHeinzmann ${ }^{c}$ and Alois Buholzer ${ }^{a}$ \\ a Institute for Diversity Education, University of Teacher Education, Lucerne, Switzerland \\ b Education Secondary Level I, University of Teacher Education of Zurich, Zurich, Switzerland \\ c InstituteforLanguage Didactics, University of Teacher Education, St. Gallen, Switzerland
}

\begin{abstract}
The present study examined what impact various constellations of acculturation orientations of immigrant students and their teachers have on the students' school adjustment. For this purpose, the study analysed the acculturation orientations of 1106 5th graders and their class teachers in Switzerland. Using multiple regression analysis, we found that immigrant students were more satisfied at school if their teachers had similar attitudes about cultural assimilation and cultural diversity and could, thus, be said to have congruent acculturation orientations. With respect to students' academic self-concept, immigrant students with a minority orientation whose teachers value cultural diversity including the heritage culture of their students showed a lower academic self-concept despite matching acculturation orientations. We interpret this result as a dilemma of teachers between the endeavour to develop culturally sensitive attitudes and behaviours and the risk to create stereotype threat and its negative effects through addressing cultural differences. Furthermore, a mismatch between the students' (bi-)national identification at school and the teacher's perception of the student as an immigrant or a native-born student could be shown to have adverse effects on the academic self-concept in the group of students with older teachers (50+ years).
\end{abstract}

\section{Introduction}

Within cross-cultural psychology, schools are considered the main acculturation context for immigrant children and youth (Berry et al. 2011). It is not surprising therefore that a long-standing debate exists about how immigrant student school adjustment can succeed and which professional attitudes and behaviours among teachers are necessary to assure and improve immigrant students' well-being and achievement at school (OECD 2015). For successful 
adjustment to a new school environment and students' well-being a trusting and respectful teacher-student-relationship is regarded as crucial (Hoti et al. 2017). There is also evidence, however, that immigrant and minority students suffer from teacher bias and low expectations regarding their school success (Nusche 2009). Consequently, teachers are believed to have a decisive impact on the school career of immigrant students.

\section{Interactive acculturation in the school context}

In line with the principle of reciprocity, we assume that acculturation in the school context is an interactive process whereby teachers and students mutually influence each other's acculturation orientations (Berry 2006). Acculturation orientations refer to attitudes and behaviours that manifest themselves in everyday intercultural encounters (Berry 2005). However, acculturation orientations of individuals are not entirely freely chosen, but are influenced by societal power relations. This also applies to the student-teacher relationship, in which the teacher has more influence and normative power with respect to the set of values, attitudes and cultural practices at school and respective expectations due to his or her dominant position in the school system. This problem is accentuated by the fact that immigrant und minority students often have teachers who are themselves part of the dominant ethnic group, tend to hold middle class norms and who do not possess any first-hand experience with migration.

Some studies on acculturation in the school context have identified assimilative tendencies (Makarova and Birman 2015), which has sparked criticism for school practices which tend to push students to culturally assimilate into the dominant culture of the receiving society, thereby ignoring that many immigrant students would prefer to maintain aspects of their heritage culture (e. g. home language, religious and cultural practices) (Baysu, Phalet, and Brown 2011). It has also been pointed out, however, that receiving countries are not homogenous entities (Van Oudenhoven and Ward 2013). Rather, attitudes and values of individuals in relation to the acceptance of cultural diversity as well as institutional practices vary within the dominant group. Consequently, different acculturation orientations among teachers are to be expected. The same goes for the acculturation orientations of immigrant students who come from very diverse social and (multi-)cultural contexts in their countries of origin as well as their receiving country and who exhibit diverse values, attitudes, and behaviours. But to date there are few, if any, empirically founded insights into the constellations of acculturation orientations of immigrant students and their teachers, and what influence a match has on the teacher-student relationship, well-being at school and educational achievement of immigrant students. This is the starting point of the current research project, entitled Acculturation of Primary School Children and their Teachers (APRIL). 
Our concept of acculturation comprises four orientations: besides a minority orientation at school, where the keeping of one's heritage culture is seen as important and a majority orientation, where identification with the dominant majority culture is seen as essential, we included a multicultural orientation, which refers to the appreciation of diversity at school and an orientation which we named 'cultural indifference', because it implies that in day-to-day school life aspects such as personality traits or friendship are considered more important than cultural background.

As far as the theoretical background of the study is concerned, we base our study on two models, the Interactive Acculturation Model (IAM) of Bourhis, Moïse, Perreault, and Senécal (1997) and the Acculturation Gap-Distress Model (Szapocznik and Kurtines 1993). According to the Interactive Acculturation Model (IAM) relational outcomes between cultural majority and immigrant groups are the product of the acculturation orientations of both parties, as well as influenced by integration policies (Bourhis, Moïse, Perreault, and Senécal 1997). The IAM predicts that congruent acculturation orientations of immigrants and members of the native-born community most likely result in consensual relational outcomes, whereas a mismatch of acculturation orientations produces problematic and conflictual relationships. However, the model has not yet served as a theoretical framework for the analysis of acculturation at school and for the interpretation of a potential match in acculturation orientations of teachers and students. The Acculturation Gap-Distress Model is characterized by a more individualistic perspective and assumes that differing acculturation orientations between adults and children produce an acculturation gap and lead to conflict and maladjustment of the children (Szapocznik and Kurtines 1993). This model too, has not been applied to the school context so far since the focus to date has been on immigrant families. Based on the theoretical assumptions of these two models, the present study analyses the constellations of acculturation orientations between immigrant students and their teachers and aims to answer the following research question: What influence do different constellations of acculturation orientations between immigrant students and their teachers exert on the students' school adjustment? The assumption is that students whose teachers have matching acculturation orientations have a better school adjustment than students whose teachers have mismatching acculturation orientations.

The term 'school adjustment' is widely used, but in an inconsistent way. According to Huges (2012), research on teacher-student-relationships and their impact on school adjustment has looked at behavioral and academic aspects of adaptation to the student's role and to the requirements of the institution. In Wentzel's (2013) concept of school adjustment, however, the student's engagement in relationships, which are able to satisfy their social and emotional needs and which foster their sense of belonging to the school are considered important. The APRIL-study uses 'school satisfaction' and 'academic self-concept' as 
indicators for school adjustment, thereby taking into account social, emotional and academic aspects of adaptation.

\section{Students' acculturation orientations and adjustment at school}

Numerous studies carried out in different cultural contexts support the integration hypothesis, which states that the acculturation orientation 'integration' is most beneficial for immigrants in different respects (Berry 2017; Nguyen and Benet-Martínez 2013). Students with an integration orientation often have a better psychosocial adaptation than students with another orientation, especially if they feel marginalised. However, there are also studies showing positive effects of a majority orientation (assimilation) regarding the psychosocial adaptation and academic success of immigrant students and studies reporting positive outcomes of immigrants with a minority orientation (separation) (Makarova and Birman 2015). Motti-Stefanidi et al. (2008) found the minority orientation to be predictive for a better psychological well-being, whereas the majority orientation was predictive of academic success, which they interpret to be a result of assimilative practices in schools. Some studies investigated the acculturation orientations of students at school and at home and showed that the most adaptive acculturation orientations depended on the acculturation domain and on the ethnic background of the student (Andriessen and Phalet 2002).

\section{Effects of teacher's acculturation orientations}

Studies at the intersection of educational research and cross-cultural psychology indicate that teachers express values in their interactions with their culturally diverse students and their teaching, which seem to influence the acculturation orientations and well-being of the students, even though they have not specifically looked at the question of matching acculturation orientations. In a Swiss sample, Makarova showed that a frequent reflection on cultural diversity in class, which could be regarded as an endorsement of a multicultural orientation as opposed to a rare reflection on cultural diversity, tended to reinforce students' identification with the Swiss majority culture and the integration orientation (2008). Of the primary school teachers investigated in another Swiss study, evidence for a relationship between the teachers' acculturation orientations and the students' well-being at school was found (Makarova and Herzog 2013): teachers with an integration orientation showed a higher diagnostic expertise in the area of social tensions and were more likely to react to students' disruptive behaviour than teachers favouring the separation or assimilation orientation. Vedder and van Geel (2012) carried out a study in the Netherlands among Muslim students (mostly of Turkish and Moroccan descent) which demonstrated that the degree of perceived discrimination sank, and the feeling of self-worth and the motivation of the learners 
increased with an increasing appreciation of the heritage cultures of the students (or their parents). Carigiet Reinhard (2012), however, did not find a significant correlation between the attitudes of primary school teachers towards acculturation (monolingually versus multilingually oriented) and the German reading skills of their students. The students of those teachers who comparatively strongly perceived the cultural diversity of the students in their class to cause additional work even performed better on the German reading test than the students of teachers who perceived this heterogeneity to be less burdensome, maybe because the former invested more time into the language education of their students.

\section{Method}

The data were collected during two regular consecutive classroom sessions. First, students completed a questionnaire including the scales concerning their school adjustment (school satisfaction and academic self-concept) and their relationship to the teacher. Second, they took a literacy test and answered sociodemographic questions, including questions about their migration background and language use (45 minutes duration). During the break (15-20 minutes), the test administrators assigned the appropriate version of the questionnaire for the second lesson for every student, according to their migration background. During the second lesson students completed a questionnaire concerning acculturation orientations and (bi-)national identification at school (45 minutes duration). The test administrators were present to answer comprehension questions and to ensure that the standardized procedure was observed. In Switzerland, primary school kids are mainly taught by one class teacher. Those class teachers also completed a questionnaire during the same two lessons in a separate room. Their questionnaire contained scales concerning their acculturation orientations and their relationship with each child.

\section{Participants}

The sample consisted of 1106 fifth-graders ( 581 female, 525 male) and 60 teachers (40 female, 20 male) in 60 school classes, in 42 schools, from eight German speaking federal states in Switzerland. Most of the students $(71 \%, n=782)$ were 11 years old, $10 \%(n=110)$ were 10 years old or younger, and $19 \%(n=210)$ were 12 years old or older. Based on their own or their parents' country of birth, 825 students were classified as having a migration background ( $n=155$ first and $\mathrm{n}=670$ second generation). They came from 81 different countries of origin ${ }^{1}$. We focused on students from five of the main immigrant groups in Switzerland: students with an Albanian $(n=206)$, Italian $(n=88)$, Portuguese $(n=45)$, Latin American $(n=24)$ and Sri Lankan Tamil $(n=57)$ background. 35\% $(n=373)$ of the students indicated being Swiss citizens only, 32\% $(n=348)$ of them indicated 
having the Swiss, as well as another citizenship, and 33\% $(n=354)$ indicated only having another citizenship.

A majority of the teachers was born in Switzerland $(n=50)$. Of the others, six were born in Germany, one in Bosnia, one in Kosovo, one in France and one in Sri Lanka. Fifty teachers had the Swiss citizenship only, four had the Swiss as well as another citizenship and six had another citizenship only. The teachers were between 20 and 65 years old (20-29 years: $n=20,30-39$ years: $n=15$, 40-49: $n=10$, and 50-65: $n=15$ ).

\section{Measures}

Acculturation orientations. To measure the four proposed acculturation orientations in the school context, we developed four scales for children's self-reported acculturation orientations (Wolfgramm, Haenni Hoti, Pautasso, Müller, Buholzer, and Künzle 2017). In the student population, the acculturation orientations 'majority orientation' (e.g. 'At school I belong to the Swiss', $a=.72$ ), 'minority orientation' (for immigrant students only) (e.g. 'During breaks I spend time with children from my other country' ${ }^{2}, a=.65$ ) and 'multicultural orientation', which comprises the appraisal of cultural diversity (e.g. 'I like it when everybody in class gets to know the different languages of their classmates', $a=.65$ ), were each measured with six items. The fourth scale labelled 'cultural indifference' consists of four items, which suggest that cultural origin is not considered relevant in school (e.g. 'At school it doesn't matter which country I come from', $a=.67$ ).

As far as the teachers' self-reported acculturation orientations are concerned it was not possible to generate the same four acculturation scales. This is first because the vast majority of the teachers in our sample had no migration background and therefore no minority orientation. Secondly, according to results of the factor analysis, the 'multicultural orientation' of the teachers also comprised aspects of recognition of the cultural heritage culture of immigrant students ('minority orientation'). And finally, the 'majority orientation' of the teachers also comprised aspects of 'cultural indifference'.

Consequently, the teachers' acculturation orientations could be assessed with two scales including a multicultural and a majority orientation. Teachers' multicultural orientation was measured by means of four items adapted from Fürstenau, Huxel, and Diekmann (2014; e.g. 'School should help students with a migration background to deal with cultural diversity in society', $a=.58$ ). Teachers' majority orientation was assessed by means of four items adapted from Fürstenau, Huxel, and Diekmann (2014; e.g. 'School should help students with a migration background to adapt to the Swiss culture', $a=.46$ ).

(Bi-)national identification. Furthermore we asked students to indicate their national identification with two items ('I consider myself to be Swiss' and 'I consider myself to be someone from my other country'). In addition, students indicated what national identification they perceived their teachers to ascribe 
to them with two items ('My teacher considers me to be Swiss' and 'My teacher considers me to be someone from my other country').

School satisfaction and academic self-concept were assessed with four items each (Venetz, Zurbriggen, and Eckhart 2014). Cronbach's alpha for the school satisfaction was $\alpha=.86$ (e.g. 'School is fun'). Cronbach's alpha for the academic self-concept was $a=.78$ (e.g. 'I am good at school').

Quality of student-teacher relationship. Finally, seven items translated and adapted from Murray and Greenberg (2000; e.g. 'I like my class teacher', $a=84$ ) probed into the quality of the relationship between students and their teacher as perceived by the students. The teachers' perspective on the relationship with their students was also measured by seven items adapted from Milatz, Glüer, Harwardt-Heinecke, Kapplera, and Ahnert (2014; e.g. 'It is easy for me to like that child', $a=.87$ ), which had to be answered for every student.

All questionnaire items were answered on a 4-point Likert scale. Students could answer with 'yes' to 'no' ( $1=$ no, $2=$ rather no, $3=$ rather yes, $4=$ yes $)$. Teachers answered the items with 'totally agree' to 'totally disagree' ( $1=$ totally disagree, 2 = rather disagree, 3 = rather agree, $4=$ totally agree).

\section{Data analysis}

Constellations of acculturation orientations between immigrant students and their teachers were considered as follows:

(1) agreement on multicultural orientation between student and teacher,

(2) agreement on majority orientation between student and teacher, whereby agreement includes mutual consent, as well as mutual refusal of the acculturation orientations. For an agreement on those two scales we used the term 'congruent acculturation orientations', as the scales concerned comprised items on the same construct but not identical items for students and teachers.

(3) The third constellation of acculturation orientations between immigrant students and their teachers considered was if the student agrees with the minority orientation and the teacher agrees with the multicultural orientation or vice versa. We use the term 'matching acculturation orientations' for this constellation as, despite the existence of differing orientations there is a content-related compatibility.

To categorize acculturation orientations as congruent and non-congruent, matching and mismatching, the agreement between students' self-reported acculturation orientations and the self-reported acculturation orientations of the teacher was considered. We used 2.5 as the cut-off value. If both student and teacher had a value above the cut-off value of 2.5 or both had a value below the cut-off, the constellation of their orientations was defined as 
'congruent' or 'matching', in the opposite case as 'non-congruent' or 'mismatching'.

To examine the relationship between the constellation of acculturation orientations and the students' school adjustment, multilevel regression analyses were carried out. School context and socio-demographic variables were taken into account as additional potential explanatory variables. The relative importance of an explanatory variable's contribution in the regression model was assessed by averaging sequential sums of squares over all orderings of explanatory variables (Grömping 2006).

The predictors were examined including non-linear terms and interactions as well as potential random class effects. The dependent variable school satisfaction had to be transformed due to heavy skewness. The variable selection was based on the Akaike information criterion (AIC). All regression analyses were carried out with the program R, version 3.4.1 (R Core Team 2017).

\section{Results}

Table 1 presents results regarding the relationship between congruent and matching acculturation orientations of student and teacher, and the two target variables 'school satisfaction' and 'academic self-concept' of the students.

The influence of the three constellations of acculturation orientations between students and teachers on school satisfaction was examined by means of multiple regression analysis, since there was no significant class effect. The analysis with and without data of students without migration background led to the same statistical model. The analysis yielded the following results (see Table 2): A congruency regarding multicultural orientation (e. g. student 'likes/dislikes it when everybody in class gets to know the different languages of their classmates' and teacher supports/does not support the idea 'that school should help students with a migration background deal with cultural diversity in society') goes hand in hand with higher student school satisfaction. In return, a lack of congruency regarding multicultural orientation is related to lower student school satisfaction.

Table 1. Results on constellations of acculturation orientations and students' school satisfaction and academic self-concept.

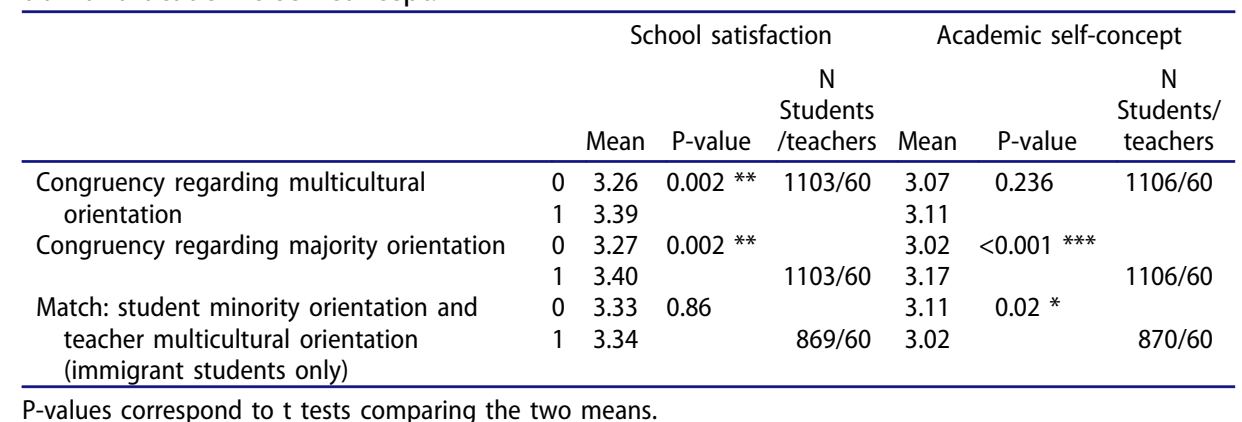


Table 2. Result of the regression analysis on the school satisfaction of primary school children.

\begin{tabular}{|c|c|c|}
\hline & Regression coefficient & Standard error \\
\hline$(\text { Intercept })^{\mathrm{a}}$ & -21.67 & $3.87^{* * *}$ \\
\hline Albanian & 4.77 & $1.66^{* *}$ \\
\hline Italian & -2.41 & 2.06 \\
\hline Latin American & 2.69 & 3.50 \\
\hline Portuguese & -0.05 & 2.70 \\
\hline Sri Lankan Tamil & 5.77 & $2.42 *$ \\
\hline Other migration background & 0.90 & 1.43 \\
\hline Gender: male ${ }^{c}$ & -3.69 & $0.99 * * *$ \\
\hline Quality of relationship with teacher & 18.42 & $1.00 * * *$ \\
\hline Age of teacher: $30-39$ years $^{d}$ & -2.16 & 1.31 \\
\hline Age of teacher: $40-49$ years & -2.96 & $1.48 *$ \\
\hline Age of teacher: 50 years and older & -4.13 & $1.31 * *$ \\
\hline Congruency regarding multicultural orientation ${ }^{\mathrm{e}}$ & 2.03 & $1.00 *$ \\
\hline Congruency regarding majority orientation ${ }^{f}$ & 2.57 & $1.08 *$ \\
\hline
\end{tabular}

$\mathrm{N}$ students $=1,086, \mathrm{~N}$ teachers $=60, \mathrm{R}^{2}=.30,{ }^{*} \mathrm{p}<.05,{ }^{* *} \mathrm{p}<.01,{ }^{* * *} \mathrm{p}<.001$

${ }^{a}$ The intercept in Tables 2 and 3 corresponds to the estimated value for the target variable if all the continuous explanatory variables are set to zero. With categorical variables, the regression coefficient indicates to what extent students from the category in question differ from students in the reference group. With continuous variables, the regression coefficient indicates how much the target variable changes if the continuous variable changes by the value 1

'The reference category is 'no migration background'

'The reference category is 'female'

'The reference category is ' $20-29$ years'

'The reference category is 'no congruency regarding multicultural orientation'

'The reference category is 'no congruency regarding majority orientation'

The same goes for the majority orientation: A congruency regarding majority orientation (assimilation) between student and teacher (both parts support the idea of assimilation of immigrant student or both parts do not agree with the idea of assimilation) is related to a significantly higher student school satisfaction than a lack of congruency (see Table 2). In other words, students whose teachers have congruent acculturation orientations are more satisfied at school. These congruent constellations of acculturation orientations between student and teacher account for $1 \%$ of the total variability of the students' satisfaction in school (calculated with $\mathrm{R}$ package relaimpo according to Grömping 2006). Evidently, it makes a difference for the students' school adjustment whether their teachers share a similar orientation with regard to acculturation. However, the quality of the teacher-student-relationship turned out to be a more dominant predictor for school satisfaction than the constellation of acculturation orientations (see Table 2). A better quality of the teacher-student-relationship, as perceived by the student, goes hand in hand with a significantly higher satisfaction at school. Since the quality of the teacher-student-relationship explains $24 \%$ of the total variability of students' school satisfaction, a good relationship with the teacher seems to play a crucial role for the students' school adjustment, independent of an existing congruency in acculturation orientations. Furthermore, demographic variables, such as ethnic identification of the student, gender, and age of the teacher also played a role (see Table 2).

Students with an Albanian and a Sri Lankan Tamil migration background showed greater school satisfaction than native-born students without 
a migration background. Boys reported significantly lower school satisfaction than girls and students with younger teachers reported significantly higher school satisfaction than students with older and more experienced teachers (see Table 2).

Next, we will look at the influence of various constellations of acculturation orientations between student and teacher on students' academic self-concept (see Table 3). In addition, we will illustrate that a mismatch regarding the self and other ascribed national identification of the student exerts a negative influence on students' academic self-concept. Since the two variables minority orientation and (bi-)national identification concerned only children with a migration background, children without an immigration background were excluded from the multiple regression analysis presented in Table $3\left(R^{2}=.22\right)$. As far as the acculturation orientations are concerned, the results do not support the assumption that a match between student and teacher with regard to a minority orientation positively affects students' academic self-concept. A match between the teacher and the student, where the student finds his or her heritage culture and language important at school and where he or she also perceives a positive attitude towards cultural diversity on the part of the teacher, went hand in hand with a lower academic self-concept of the students (see Table 3). The question why immigrant students with a minority orientation, whose teachers seem to value cultural

Table 3. Result of the regression analysis on the academic self-concept of immigrant primary school children.

\begin{tabular}{|c|c|c|}
\hline & $\begin{array}{l}\text { Regression } \\
\text { Coefficient }\end{array}$ & $\begin{array}{c}\text { Standard } \\
\text { Error }\end{array}$ \\
\hline 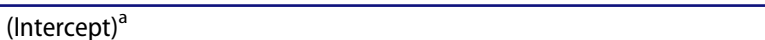 & 1.59 & $0.16 * * *$ \\
\hline Gender: male ${ }^{b}$ & 0.21 & $0.04 * * *$ \\
\hline Quality of relationship with teacher & 0.26 & $0.04 * * *$ \\
\hline Quality of relationship with student & 0.09 & $0.03 * *$ \\
\hline Citizenship: dual ${ }^{\mathrm{c}}$ & -0.10 & $0.05 *$ \\
\hline Citizenship: other than Swiss & -0.14 & $0.05 * *$ \\
\hline Educational resources: $11-25$ books at home ${ }^{d}$ & 0.19 & $0.05 * * *$ \\
\hline Educational resources: $26-100$ books at home & 0.30 & $0.05 * * *$ \\
\hline Educational resources: $101-200$ books at home & 0.50 & $0.07 * * *$ \\
\hline Educational resources: more than 200 books at home & 0.48 & $0.08 * * *$ \\
\hline Age of teacher: $30-39$ years $^{\mathrm{e}}$ & 0.00 & 0.05 \\
\hline Age of teacher: $40-49$ years & 0.06 & 0.06 \\
\hline Age of teacher: 50 years and older & 0.04 & 0.06 \\
\hline Mismatch regarding national identification ${ }^{f}$ & 0.13 & $0.07^{+}$ \\
\hline Match regarding minority orientation ${ }^{9}$ & -0.08 & $0.04 *$ \\
\hline Age of teacher: $30-39$ years $*$ national identification mismatch & -0.12 & 0.11 \\
\hline Age of teacher: $40-49$ years * national identification mismatch & -0.14 & 0.12 \\
\hline Age of teacher: 50 years and older * national identification mismatch & -0.34 & $0.10 * * *$ \\
\hline
\end{tabular}

$\mathrm{N}$ students $=787, \mathrm{~N}$ teachers $=60, \mathrm{R}^{2}=.22,{ }^{+} \mathrm{p}<0.1,{ }^{*} \mathrm{p}<.05,{ }^{* *} \mathrm{p}<.01,{ }^{* * *} \mathrm{p}<.001$

${ }^{a}$ The intercept in Tables 2 and 3 corresponds to the estimated value for the target variable if all the continuous explanatory variables are set to zero. With categorical variables, the regression coefficient indicates to what extent students from the category in question differ from students in the reference group. With continuous variables, the regression coefficient indicates how much the target variable changes if the continuous variable changes by the value 1

bThe reference category is 'female'

'The reference category is 'Swiss citizenship'

'The reference category is ' $0-10$ books at home'

'The reference category is ' $20-29$ years'

'The reference category is 'match regarding national identification'

${ }^{9} T$ The reference category is 'no match regarding minority orientation' 
diversity, show a lower academic self-concept will be addressed in the discussion section.

With respect to their (bi-)national identification, students could indicate that they identify as Swiss at school, that they identify with another country when at school (e. g. to feel as an Albanian, Portuguese, Italian, Sri Lankan Tamil, Latin-American etc.), that they feel attached to Switzerland and another country and thereby have a binational identification, or that no national identification was important to them in the school context. A mismatch between the students' (bi-)national identification at school and the teacher's perception of the student as an immigrant or a nativeborn student, as reported by the students (e.g. the student reports identifying as a Swiss but feels that the teacher considers him/her to be a Latino/Latina or the other way around) could be shown to negatively affect their academic self-concept, but only in the group of students with older and more experienced teachers (50 years and older) (see Table 3). Consequently, there is an interaction between the age of the teacher and the mismatch regarding national identification, with a mismatch negatively affecting academic self-concept. In other words, students whose teachers have matching views of the students' (bi-)national identification have a better academic self-concept. Together, the mismatch regarding self and other ascribed (bi-)national identification and the constellation regarding minority orientation of the student and multicultural orientation of the teacher account for $2.5 \%$ of the total variability of the students' academic self-concept.

However, with a better quality of the teacher-student-relationship, student academic self-concept seems to improve independently from the match or mismatch regarding acculturation orientations and (bi-)national identification (see Table 3). Furthermore, girls, students without Swiss citizenship, and students with few educational resources at home (max. 10 books) were shown to have a lower academic self-concept (see Table 3). It needs to be clarified that the most important predictor of students' academic self-concept is the educational background of the students (as measured by the number of books at home) explaining $7.8 \%$ of the total variability of the academic self-concept and not the migration background of the students or matching/mismatching acculturation orientations between teachers and students.

\section{Discussion}

Our results show that immigrant students' school satisfaction and academic selfconcept are affected by matching acculturation orientations between teacher and student. Regarding school satisfaction, the results were in line with the presumed positive effect: congruent multicultural and majority orientations between teacher and student went hand in hand with greater school satisfaction. In other words, if students and teachers share the same values and attitudes towards cultural diversity - by either supporting or dismissing a multicultural orientation this seems to benefit school. Immigrant students also seem to be more satisfied at 
school if their attitudes and behaviours with respect to the adaptation to the dominant majority culture match with their teachers' expectations, including either the acceptance or dismissal of the assimilation orientation. These results support the tenets of the Interactive Acculturation Model and of the Acculturation-Gap Distress Model, according to which matching acculturation orientations between immigrants and native-born result in more positive relational outcomes and better adjustment. However, given the power imbalance within the teacher-student relationship, the question arises as to how these congruent acculturation orientations occur and to what extent a teacher, whether intentionally or not, is able to impose his or her values and attitudes upon the students. In the case of a majority orientation match (assimilation) it could be that the students adapt to the orientation of their teachers or the values regarding acculturation that are perceptible at school, in order to prevent conflictual relationships and to reduce stress. As pointed out by Makarova and Birman (2015), an assimilative orientation in an assimilative environment could indeed prove to be most successful. Similarly, congruent multicultural orientations, too, could be an expression of an adaptation to the multicultural, diversity friendly values of the teachers. However, for interpretation purposes it should be pointed out that our operationalization of teachers' acculturation orientation reflects teachers' attitudes on how schools should deal with cultural diversity, but not necessarily how they deal with cultural diversity themselves.

Regarding academic self-concept, no positive effect of matching acculturation orientations could be found. Other than expected, a match regarding minority orientation of students with multicultural orientation of the teachers was negatively related to the students' academic self-concept. It is important to recognise that a match regarding a minority orientation is particular in the sense that most teachers are members of the dominant cultural majority and as such, unlike the immigrant students, cannot have a minority orientation themselves. The match regarding acculturation orientations, in this case, consists of a minority orientation on the part of the immigrant students and a multicultural orientation on the part of the teachers. A negative relationship with the academic self-concept exists, on the one hand, among immigrant students who do not deem their culture of origin to be important in the school context and who have teachers, who exhibit a rather critical stance towards cultural diversity at school. Such a school context, which is directed at cultural homogeneity, does not seem to be beneficial for immigrant students' academic self-concept. This is consistent with the findings of Vedder and van Geel (2012), that appreciation of students' heritage culture was related to increased motivation of the learners. On the other hand, the same negative relationship with immigrant students' academic self-concept can be found among immigrant students who value their heritage culture as important and whose teachers welcome cultural diversity at school. We can only speculate about the interactions between teacher and students and school context variables 
that might explain this result, since we de did not capture the academic expectations of the immigrant students of these 'diversity-friendly' teachers. One possible explanation leads us to the insights of research on the stereotype threat effect. This research shows that elementary school kids perform worse after activation of negative stereotypes about their own group, than under non-threatening conditions (e.g. Ambady et al. 2001). If a 'diversity-friendly' teacher discusses migration with a student, whose identification with his/her heritage culture is high, thereby ignoring negative stereotypes about 'low achieving immigrant students', this could have negative consequences for the academic self-concept (and the academic achievement) of the student. Therefore, Weber, Appel, and Kroneberger (2015) advise teachers to highlight the similarities between the cultures of immigrants and the cultures of the native-born in situations where stereotype threat effects could be at play. This constitutes a dilemma for teachers when dealing with immigrant students: They should practice culturally sensitive teaching, but if they address cultural diversity in the class they risk evoking counterproductive effects through the activation of a stereotype threat, such as a lower academic self-concept.

Finally, a mismatch regarding (bi-)national identification had a negative effect on students' academic self-concept, however only when the teacher was 50 years or older. In $76 \%$ of the cases, the teacher did not recognize that a child perceived to be an immigrant child actually perceived him-/herself as Swiss. Also, in $24 \%$ of the cases, the teacher did not recognize that a child perceived to be Swiss perceived him-/herself as belonging to another nation. It cannot be ruled out that this mismatch goes hand in hand with a tendency to be prejudiced towards immigrants, since some studies show prejudice against stigmatised groups to be more prevalent among older groups of persons (Stewart, von Hippel, and Radvansky 2009). However, older teachers may have been less prepared to deal with cultural heterogeneity in school classes during their studies. For this reason, these teachers, in particular, could benefit from further training. Additionally, the question as to how to match a school system, which still tends to reproduce cultural homogeneity and social inequality to the different needs, values, attitudes and behaviours of its diverse student population, remains crucial.

The present study has a number of limitations, which have to be taken into account for the interpretation of results. The acculturation orientations of students and teachers could not be assessed completely equivalently. On the one hand, this is due to their different roles at school and, on the other hand, their age difference. The appraisal of the acculturation orientations of their teachers was challenging for primary school students, a circumstance that we attribute to the relatively young age of the students, among other things. With respect to the teachers, on the other hand, the acculturation orientations were operationalized by their attitudes regarding how schools should behave towards children with a migration background, but not their personal attitudes and behaviours. Finally, the results are based on cross-sectional data. Further 
analyses will include the full longitudinal data associated with the APRIL-study, with a second measurement point in 2017.

\section{Note}

1. Afghanistan, Albania, Algeria, Angola, Argentina, Australia, Austria, Bangladesh, Belgium, Bosnia-Herzegovina, Brazil, Burkina Faso, Cambodia, Cameroon, Canada, China, Columbia, Congo, Costa Rica, Croatia, Cuba, Czech Republic, Denmark, Dominican Republic, Ecuador, Egypt, England, Eritrea, Ethiopia, Finland, France, Gambia, Germany, Ghana, Greece, Hungary, India, Iran, Iraq, Italy, Ivory Coast, Japan, Kenya, Korea, Laos, Lebanon, Lithuania, Macedonia, Morocco, Mexico, Moldavia, Montenegro, Nepal, Netherlands, Nigeria, Pakistan, Palestine, Peru, Philippines, Poland, Portugal, Romania, Russia, Serbia, Sierra Leone, Slovakia, Slovenia, Somalia, South Africa, Spain, Sri Lanka, Sweden, Syria, Thailand, Tibet, Tunisia, Turkey, Ukraine, USA, Uzbekistan, Vietnam.

2. The expression 'my other country' was adapted to our focused immigrant groups (e.g. Italy etc.). So, in the Albanian version of the questionnaire, for example, the item would read 'During breaks I spend time with Albanian children'.

\section{Disclosure statement}

No potential conflict of interest was reported by the authors.

\section{Funding}

This research was supported by the Swiss National Science Foundation [100019_159365/1].

\section{Notes on contributors}

Andrea Haenni Hoti earned her doctorate in educational sciences at the University of Fribourg (Switzerland) with a doctoral thesis on the topic of nationalism and xenophobia among Swiss youth. She was a visiting scholar at Columbia University in New York (USA) and at the University of Hamburg (Germany). Andrea Haenni also held a guest professorship at the University of Toronto (Canada) and at the University of Augsburg (Germany). She is currently Professor of Educational and Social Sciences at the University of Teacher Education in Lucerne (Switzerland), where she teaches in the teacher education program. She carried out research projects in the field of general pedagogy and transcultural educational sciences. Her main research focus is on cultural diversity, acculturation, multilingualism and equity in schools.

Christine Wolfgramm earned her doctorate in Psychology at the University of Berne (Switzerland) with a thesis about cultural identity and school success. She was a research fellow at the Free University of Berlin (Germany). Christine Wolfgramm was a research collaborator at the institute of the Management and the Economics of the Education in Zug (Switzerland) and at the University of Teacher Education in Lucerne (Switzerland), and she was a lecturer at the University of Teacher Education in Zug (Switzerland). She currently is senior lecturer at the University of Teacher Education in Zurich (Switzerland). Her research 
focus is on cultural identity, self-concept, acculturation and equity in schools, but also the professional development and self-management of teachers.

Marianne Müller earned her doctorate in mathematics at the University of Zurich with a doctoral thesis on algebra. Within the framework of a postdoctoral fellowship of the Swiss National Science Foundation she then worked at the Queen Mary \& Westfield College of the University of London. As a research associate at the Institute for Social and Preventive Medicine in Berne she was jointly responsible for the design and data analysis in social and health science studies and thus got acquainted with the practical aspects of statistics. She is currently Professor of Statistics at Zurich University of Applied Sciences and a Lecturer for Biostatistics at ETH Zurich. Marianne Müller is an expert in the field of scale development, in particular Rasch modeling and is involved in the software development for Rasch modeling within an international team, the European Rasch Training Group (ERTG).

Sybille Heinzmann holds a doctorate in English Applied Linguistics from the University of Fribourg (Switzerland). Her thesis deals with affective variables in language learning. She was a research fellow at the University of Teacher Education in Lucerne (Switzerland), a lecturer at the University of Fribourg and the University of Teacher Education in Fribourg and a visiting scholar at the Department of Second Language Studies at the University of Hawai'i at Mānoa (USA). Currently, she is a research collaborator at the Institute of foreign language didactics and lecturer at the University of Teacher Education in St. Gallen (Switzerland). Her research focuses on multilingualism and diversity in the school setting. Her main research topics are mobility, language learning motivation, language attitudes, and intercultural skills.

Alois Buholzer obtained a doctorate in educational sciences from the University of Zurich (Switzerland) with a doctoral thesis on the topic of school reforms at public elementary schools. Since 2007 he has been Professor of Educational and Social Sciences at the University of Teacher Education Lucerne (Switzerland). In 2006 he was appointed to build up the Research Institute 'School and Heterogeneity' at the newly founded University of Teacher Education Lucerne whose direction he also currently holds. Alois Buholzer is leading numerous research projects, such as, for example, the evaluation of the national program and the projects 'Promotion of Integration' on behalf of the Federal Office of Migration. His research interest is in training/learning research with a main focus on research on 'diversity', 'inclusion' as well as 'acts of teachers in inclusive schools'. Alois Buholzer's latest research project deals with the formative assessment of teachers in inclusive school classes.

\section{References}

Ambady, N., M. Shih, A. Kim, and T. L. Pittinsky. 2001. "Stereotype Susceptibility in Children: Effects of Identity Activation on Quantitative Performance." Psychological Science 12: 385-390. doi:10.1111/1467-9280.00371.

Andriessen, I., and K. Phalet. 2002. "Acculturation and School Success: A Study among Minority Youth in the Netherlands." Intercultural Education 13 (1): 21-36. doi:10.1080/ 14675980120112913.

Baysu, G., K. Phalet, and R. Brown. 2011. "Dual Identity as a Two-Edged Sword: Identity Threat and Minority School Performance." Social Psychology Quarterly 74 (2): 121-143. doi:10.1177/0190272511407619.

Berry, J. W. 2005. "Acculturation: Living Successfully in Two Cultures." International Journal of Intercultural Relations 29 (6): 697-712. doi:10.1016/j.jijintrel.2005.07.013. 
Berry, J. W. 2006. "Mutual Attitudes among Immigrants and Ethnocultural Groups in Canada." International Journal of Intercultural Relations 30 (6): 719-734. doi:10.1016/j. ijintrel.2006.06.004.

Berry, J. W., ed. 2017. Mutual Intercultural Relations. Cambridge: Cambridge University Press. Berry, J. W., Y. H. Poortinga, S. M. Breugelmans, A. Chasiotis, and D. L. Sam, eds. 2011. Crosscultural Psychology. Research and Applications. 3rd ed. Cambridge: Cambridge University Press.

Bourhis, R. Y., L. C. Moïse, S. Perreault, and S. Sacha. 1997. "Towards an Interactive Acculturation Model: A Social Psychological Approach." International Journal of Psychology 32 (6): 369-386. doi:10.1080/002075997400629.

Carigiet Reinhard, T. 2012. Schulleistungen und Heterogenität: Eine Mehrebenenanalytische Untersuchung der Bedingungsfaktoren der Schulleistungen am Ende der dritten Primarschulklasse [School Performance and Heterogeneity: A Multi-Level Analysis of the Determinants of School Performance at the End of the Third Primary School Class]. Berne: Haupt Verlag.

Fürstenau, S., K. Huxel, and F. Diekmann. 2014. Fragebogen MIKS - Mehrsprachigkeit als Handlungsfeld Interkultureller Schulentwicklung [Questionnaire MIKS - Multilingualism as a Field of Action for Intercultural School Development]. https://www.uni-muenster.de/ EW/forschung/projekte/8205.shtml

Grömping, U. 2006. "Relative Importance of Linear Regression in R: The Package Relaimpo." Journal of Statistical Software 17 (1): 1-27. doi:10.18637/jss.v017.i01.

Hoti, A. H., S. Heinzmann, M. Müller, and A. Buholzer. 2017. "Psychosocial Adaptation and School Success of Italian, Portuguese and Albanian Students in Switzerland: Disentangling Migration Background, Acculturation and the School Context." Journal of International Migration and Integration 18 (1): 85-106. doi:10.1007/s12134-015-0461-x.

Huges, J. N. 2012. "Teacher-Student-Relationships and School Adjustment: Progress and Remaining Challenges." Attachment and Human Development 14 (3): 319-327. doi:10.1080/14616734.2012.672288.

Makarova, E. 2008. Akkulturation und kulturelle Identität. Eine empirische Studie bei Jugendlichen mit und ohne Migrationshintergrund in der Schweiz [Acculturation and Cultural Identity. An Empirical Study among Young People with and without a Migration Background in Switzerland]. Berne: Haupt Verlag.

Makarova, E., and D. Birman. 2015. "Cultural Transition and Academic Achievement of Students from Ethnic Minority Backgrounds: A Content Analysis of Empirical Eesearch on Acculturation." Educational Research 57 (3): 305-330. doi:10.1080/00131881.2015.1058099.

Makarova, E., and W. Herzog. 2013. "Teachers' Acculturation Attitudes and Their Classroom Management: An Empirical Study among Fifth-Grade Primary School Teachers in Switzerland." European Educational Research Journal 12 (2): 256-269. doi:10.2304/ eerj.2013.12.2.256.

Milatz, A., M. Glüer, E. Harwardt-Heinecke, G. Kapplera, and L. Ahnert. 2014. "The Student-Teacher Relationship Scale Revisited: Testing Factorial Structure, Measurement Invariance and Validity Criteria in German-Speaking Samples." Early Childhood Research Quarterly 29 (3): 357-368. doi:10.1016/j.ecresq.2014.04.003.

Motti-Stefanidi, F., V. Pavlopoulos, J. Obradovic, and A. S. Masten. 2008. "Acculturation and Adaptation of Immigrant Adolescent in Greek Urban Schools." International Journal of Psychology 43 (1): 45-58. doi:10.1080/00207590701804412.

Murray, C., and M. T. Greenberg. 2000. "Children's Relationship with Teachers and Bonds with School: An Investigation of Patterns and Correlates in Middle Childhood." Journal of School Psychology 38 (5): 423-445. doi:10.1016/S0022-4405(00)00034-0.

Nguyen, A.-M. T. D., and V. Benet-Martínez. 2013. "Biculturalism and Adjustment: A Meta-Analysis." Journal of Cross-Cultural Psychology 44 (1): 122-159. doi:10.1177/0022022111435097. 
Nusche, D. 2009. "What Works in Migrant Education? A Review of Evidence and Policy Options." OECD Education Working Papers No. 22, Paris: OECD Publishing. doi: 10.1787/ 227131784531.

Organisation for Economic Co-operation and Development OECD. 2015. Immigrant Students at School: Easing the Journey Towards Integration. http://www.oecd.org/education/immi grant-students-at-school-9789264249509-en.htm

R Core Team. 2017. R: A Language and Environment for Statistical Computing. Vienna, Austria: R Foundation for Statistical Computing. http://www.R-project.org/

Silvana., W., M. Appel, and N. Kronberger. 2015. "Stereotype Threat and the Cognitive Performance of Adolescent Immigrants: The Role of Cultural Identity Strength." Contemporary Educational Psychology 42: 71-81. doi:10.1016/j.cedpsych.2015.05.001.

Stewart, B. D., W. von Hippel, and G. A. Radvansky. 2009. "Age, Race, and Implicit Prejudice: Using Process Dissociation to Separate the Underlying Components." Psychological Science 20 (2): 164-168. doi:10.1111/j.1467-9280.2009.02274.x.

Szapocznik, J., and W. M. Kurtines. 1993. "Family Psychology and Cultural Diversity: Opportunities for Theory, Research, and Application." American Psychologist 48: 400-407. doi:10.1037/0003-066X.48.4.400.

Van Oudenhoven, J. P., and C. Ward. 2013. "Fading Majority Cultures: The Implications of Transnationalism and Demographic Changes for Immigrant Acculturation." Journal of Community and Applied Social Psychology 23 (2): 81-97. doi:10.1002/casp.2132.

Vedder, P., and M. van Geel. 2012. "Immigrant Youth and Discrimination." In The Impact of Immigration on Children's Development, edited by C. G. Coll, 99-121. Basel: Karger.

Venetz, M., C. Zurbriggen, and M. Eckhart. 2014. "Entwicklung und erste Validierung einer Kurzversion des "Fragebogens zur Erfassung von Dimensionen der Integration von Schülern (FDI 4-6)" Von Haeberlin, Moser, Bless und Klaghofer [Development and Fist Validation of a Short Version of the "Questionnaire to Measure Dimensions of Students' Integration (FDI 4-6)" from Haeberlin, Moser, Bless Und Klaghofer]." Empirische Sonderpädagogik 6 (2): 99-113.

Wentzel, K. R. 2013. "School Adjustment." In Handbook of Psychology: Educational Psychology, edited by W. M. Reynolds, G. E. Miller, and I. B. Weiner, 213-231. Hoboken, NJ, US: John Wiley \& Sons. doi:10.1002/9781118133880.hop207010.

Wolfgramm, C., A. H. Hoti, J. Pautasso, M. Müller, A. Buholzer, and K. Roland 2017. "Akkulturationsorientierungen von Grundschulkindern [Acculturation Orientations of Primary School Children]." Poster presented at the 5. Conference for the Gesellschaft für Empirische Bildungsforschung (GEBF), Heidelberg, March 13-15. doi:10.13140/RG.2.2.20438.34886. 